\title{
Dental Drug Information Applications: New Initiative Project in Saudi Arabia
}

Yousef Ahmed Alomi*, iD BSc. Pharm, MSc. Clin Pharm, BCPS, BCNSP, DiBA, CDE Critical Care Clinical Pharmacists TPN Clinical Pharmacist, Freelancer Business Planner, Content Editor, and Data Analyst, Riyadh, SAUDI ARABIA

Hanin Sumaydan Saleam Aljohani Ministry of Health, Riyadh, SAUDI ARABIA. Amnah Abdulaziz Al Shams

Imam Abdulrahman Bin Faisal University, Dammam, SAUDI ARABIA.

Sukinah Abdulaziz Mohammed Alshams

Almadar Diamond Dental Complex, Alhasa, SAUDI ARABIA.

\section{Correspondence:}

Dr. Yousef Ahmed Alomi, BSc. Pharm, MSc. Clin Pharm, BCPS, BCNSP, DiBA, CDE

Critical Care Clinical Pharmacists

TPN Clinical Pharmacist, Freelancer

Business Planner, Content Editor, and

Data Analyst, P.O.BOX 100, Riyadh

11392, Riyadh, SAUDI ARABIA

Phone no: +966504417712

E-mail:yalomi@gmail.com

Received: 12-11-2020

Approved: 15-1-2021

Copyright: $\odot$ the author(s),publisher and licensee Pharmacology, Toxicology and Biomedical Reports. This is an open-access article distributed under the terms of the Creative Commons Attribution NonCommercial License, which permits unrestricted non-commercial use, distribution, and reproduction in any medium, provided the original work is properly cited.

This is an open access article distributed under the terms of the Creative Commons Attribution-NonCommercial-ShareAlike 4.0 License

Access this article online

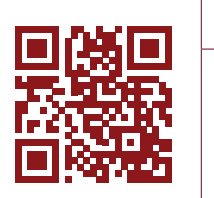

www.ptbreports.org

DOI:

10.5530/PTB.2021.7.13

\begin{abstract}
Objectives: The dental medications information application is one of the grave elements in dental practice. Therefore, the review of the updated mobile applications of dental drug information is swotted. Methods: It was revitalized of the literature on the dental drug information mobile software includes the PubMed and Medline search on this topic in numerous methods. The current project of drug information applications reconnoiters through descriptions with accent on market analysis, SWOT analysis, project team, cost management, quality requirements, and risk factors linked issues. Nominated applications had been invigorated, counting the software name, coverage of the medications, frequency updating, and subscription-related. Results: There is no examination about dental medication's mobile applications. There is more than fifteen mobile software suitable for dental providers. The project should be realized through project management professionals tools. The choosing of dental applications includes drug information based on numerous factors, coverage of the scientific data, the level of knowledge, and cost of the subscription. The advantages and disadvantages had studied throughout. Conclusion: The drug information resources with mobile applications are useful and easily reachable for all dental practitioners' specialties. Therefore, the employment of the dental applications of drug information is highly suggested in dental care.

Key words: Dental, Drug, Information, Application, Saudi Arabia.
\end{abstract}

\section{INTRODUCTION}

The classification of drug information resources applied in the dental care. There are numerous types of drug information resources. It comprised textbooks, the internet or online, and mobile applications. Besides, some drug information references came as application only. The use of new applications through the android or Microsoft operating system or newly Hawaii are easier to use, more manageable to the resources, and more friendly. Several category applications have included disease diagnosis, drug reference, and literature search. ${ }^{1}$ Few studies deliberated the knowledge assessment of drug information resources. ${ }^{2}$ There was underutilization of dental drug information applications and rarely employ of the new applications. ${ }^{2}$ In the coming years, more recent technology towards the mobile application system. ${ }^{3,4}$ As a result, the discussion of the dental applications of drug information resources is in high claim. The authors were not familiar with any review about dental drug information resources in mobile applications format locally or the Middle East and the rest of the world. The aim of the current study is to declare the drug information resources in the dental care.

\section{METHODS}

It is a literature review of drug information reference applications for dentists or drug information resources websites employed during dental care. The PubMed search of drug information resources website and the dentist or drug information resources website and dentistry or drug information references website. The word is applied as a general term, not a subject term. The search encompassed all types of studies Clinical Study, Clinical Trial, Clinical Trial, Phase I, Clinical Trial, Phase II, Clinical Trial, Phase III, Clinical Trial, Phase IV, Controlled Clinical Trial, Meta-Analysis, Observational Study, Practice Guideline, Randomized Controlled Trial, Review and Systematic Review. The searching date from 1985 to May 2021. The Pubmed search words counting as follows:

\section{Dental Application Software Drug} Information Filters: Full text, Humans, English

((“dental health services"[MeSH Terms] OR ("dental"[All Fields] AND "health"[All Fields] AND "services"[All Fields]) OR "dental health services"[All Fields] OR "dental"[All Fields] OR "dentally"[All Fields] OR "dentals"[All Fields]) AND ("applicabilities"[All Fields] OR "applicability”[All Fields] OR "application”[All Fields] OR "applications"[All Fields] OR "applicative"[All Fields]) AND ("software" [MeSH Terms] OR "software"[All Fields] OR "software s"[All Fields] OR "softwares"[All Fields]) AND "drug"[All Fields] AND ("inform"[All Fields] OR “informal”[All Fields] OR “informality”[All Fields] OR "informally"[All Fields] OR “informant"[All Fields] OR “informant”[All Fields] OR “informants"[All Fields] OR "information"[All Fields] OR "information"[All Fields] OR “informational”[All Fields] 
OR “information"[All Fields] OR "informative"[All Fields] OR "informatively"[All Fields] OR “informativeness"[All Fields] OR "informativity"[All Fields] OR “informed"[All Fields] OR "informer"[All Fields] OR "informers"[All Fields] OR "informing"[All Fields] OR “informs"[All Fields])) AND ((fft[Filter]) AND (humans[Filter]) AND (english[Filter]))

Dental Application Drug Information Filters: Full text, Humans, English

((“dental health services"[MeSH Terms] OR ("dental”[All Fields] AND "health"[All Fields] AND "services"[All Fields]) OR "dental health services"[All Fields] OR "dental"[All Fields] OR "dentally"[All Fields] OR "dentals"[All Fields]) AND ("applicabilities"[All Fields] OR “applicability"[All Fields] OR "application"[All Fields] OR “applications" [All Fields] OR "applicative"[All Fields]) AND "drug"[All Fields] AND ("inform"[All Fields] OR "informal"[All Fields] OR "informality"[All Fields] OR "informally"[All Fields] OR "informant"[All Fields] OR "informant"[All Fields] OR "informants"[All Fields] OR "information"[All Fields] OR "information"[All Fields] OR “informational" [All Fields] OR "information"[All Fields] OR "informative"[All Fields] OR "informatively"[All Fields] OR "informativeness"[All Fields] OR "informativity"[All Fields] OR "informed"[All Fields] OR "informer"[All Fields] OR "informers"[All Fields] OR "informing"[All Fields] OR "informs"[All Fields])) AND ((fft[Filter]) AND (humans[Filter]) AND (english[Filter]))

Dental Application Drug Information Filters: Full text, Humans, English

((“dental health services"[MeSH Terms] OR ("dental”[All Fields] AND "health"[All Fields] AND "services"[All Fields]) OR "dental health services"[All Fields] OR "dental"[All Fields] OR "dentally"[All Fields] OR "dentals"[All Fields]) AND ("appl plant sci"[Journal] OR "apps"[All Fields]) AND "drug"[All Fields] AND ("inform"[All Fields] OR "informal"[All Fields] OR "informality"[All Fields] OR "informally" [All Fields] OR "informant"[All Fields] OR "informant"[All Fields] OR "informants"[All Fields] OR "information"[All Fields] OR “information"[All Fields] OR "informational"[All Fields] OR “information"[All Fields] OR "informative"[All Fields] OR "informatively"[All Fields] OR "informativeness"[All Fields] OR "informativity" [All Fields] OR "informed"[All Fields] OR "informer"[All Fields] OR "informers"[All Fields] OR "informing"[All Fields] OR "informs"[All Fields])) AND ((fft[Filter]) AND (humans[Filter]) AND (english[Filter]))

Dental Drug Information Software Filters: Full text, Humans, English

((“dental health services”[MeSH Terms] OR (“dental”[All Fields] AND "health"[All Fields] AND "services"[All Fields]) OR "dental health services"[All Fields] OR "dental"[All Fields] OR "dentally"[All Fields] OR "dentals"[All Fields]) AND "drug"[All Fields] AND ("inform"[All Fields] OR "informal"[All Fields] OR "informality"[All Fields] OR "informally" [All Fields] OR "informant" [All Fields] OR "informant"[All Fields] OR "informants"[All Fields] OR "information"[All Fields] OR “information" [All Fields] OR "informational"[All Fields] OR "informations"[All Fields] OR "informative"[All Fields] OR "informatively"[All Fields] OR "informativeness"[All Fields] OR "informativity" [All Fields] OR "informed" [All Fields] OR "informer" [All Fields] OR "informers"[All Fields] OR "informing"[All Fields] OR "informs"[All Fields]) AND ("software"[MeSH Terms] OR "software"[All Fields] OR "software s"[All Fields] OR "softwares"[All Fields])) AND ((fft[Filter]) AND (humans[Filter]) AND (english[Filter]))
Mobile Application Dental Drug Information Filters: Full text, Humans, English

((“mobile applications"[MeSH Terms] OR ("mobile"[All Fields] AND "applications"[All Fields]) OR "mobile applications"[All Fields] OR ("mobile"[All Fields] AND "app"[All Fields]) OR "mobile app"[All Fields]) AND ("dental health services"[MeSH Terms] OR ("dental"[All Fields] AND "health"[All Fields] AND "services"[All Fields]) OR "dental health services"[All Fields] OR "dental"[All Fields] OR "dentally"[All Fields] OR "dentals"[All Fields]) AND "drug"[All Fields] AND ("inform"[All Fields] OR "informal" [All Fields] OR "informality" [All Fields] OR "informally" [All Fields] OR "informant"[All Fields] OR "informant"[All Fields] OR "informants"[All Fields] OR "information"[All Fields] OR "information"[All Fields] OR "informational"[All Fields] OR "information"[All Fields] OR "informative"[All Fields] OR "informatively"[All Fields] OR "informativeness"[All Fields] OR "informativity"[All Fields] OR "informed"[All Fields] OR "informer"[All Fields] OR "informers"[All Fields] OR "informing"[All Fields] OR "informs"[All Fields])) AND ((fft[Filter]) AND (humans[Filter]) AND (english[Filter]))

Mobile Phone Dental Drug Information Filters: Full text, Humans, English

(("cell phone"[MeSH Terms] OR ("cell"[All Fields] AND "phone"[All Fields]) OR "cell phone"[All Fields] OR ("mobile"[All Fields] AND "phone"[All Fields]) OR "mobile phone"[All Fields]) AND ("dental health services"[MeSH Terms] OR ("dental"[All Fields] AND "health"[All Fields] AND "services"[All Fields]) OR "dental health services"[All Fields] OR "dental"[All Fields] OR "dentally"[All Fields] OR "dentals"[All Fields]) AND "drug"[All Fields] AND ("inform"[All Fields] OR "informal"[All Fields] OR "informality"[All Fields] OR "informally"[All Fields] OR "informant"[All Fields] OR "informant"[All Fields] OR "informants"[All Fields] OR "information"[All Fields] OR “information"[All Fields] OR "informational"[All Fields] OR "information"[All Fields] OR "informative"[All Fields] OR "informatively"[All Fields] OR "informativeness"[All Fields] OR "informativity"[All Fields] OR "informed"[All Fields] OR "informer"[All Fields] OR "informers"[All Fields] OR "informing"[All Fields] OR "informs"[All Fields])) AND ((fft[Filter]) AND (humans[Filter]) AND (english[Filter]))

Mobile Phone Dentist Drug Information Filters: Full text, Humans, English

(("cell phone"[MeSH Terms] OR ("cell" [All Fields] AND "phone"[All Fields]) OR "cell phone"[All Fields] OR ("mobile"[All Fields] AND "phone"[All Fields]) OR "mobile phone"[All Fields]) AND ("dentist s"[All Fields] OR "dentists"[MeSH Terms] OR "dentists"[All Fields] OR "dentist"[All Fields]) AND "drug"[All Fields] AND ("inform"[All Fields] OR "informal"[All Fields] OR "informality"[All Fields] OR “informally" [All Fields] OR "informant" [All Fields] OR "informant"[All Fields] OR “informants"[All Fields] OR "information"[All Fields] OR "information"[All Fields] OR "informational"[All Fields] OR "information"[All Fields] OR "informative"[All Fields] OR "informatively"[All Fields] OR "informativeness"[All Fields] OR "informativity" [All Fields] OR "informed" [All Fields] OR "informer"[All Fields] OR "informers"[All Fields] OR "informing"[All Fields] OR "informs"[All Fields])) AND ((fft[Filter]) AND (humans[Filter]) AND (english[Filter]))

Mobile Phone Dentistry Drug Information Filters: Full text, Humans, English

(("cell phone"[MeSH Terms] OR ("cell"[All Fields] AND "phone"[All Fields]) OR "cell phone"[All Fields] OR ("mobile"[All Fields] 
AND "phone"[All Fields]) OR "mobile phone"[All Fields]) AND ("dentistry"[MeSH Terms] OR "dentistry"[All Fields] OR "dentistry s"[All Fields]) AND "drug”[All Fields] AND ("inform”[All Fields] OR “informal”[All Fields] OR “informality"[All Fields] OR "informally"[All Fields] OR "informant"[All Fields] OR "informant"[All Fields] OR “informants"[All Fields] OR “information”[All Fields] OR “information"[All Fields] OR “informational"[All Fields] OR “information"[All Fields] OR “informative”[All Fields] OR "informatively"[All Fields] OR “informativeness"[All Fields] OR “informativity”[All Fields] OR “informed”[All Fields] OR “informer" [All Fields] OR “informers”[All Fields] OR “informing”[All Fields] OR “informs"[All Fields])) AND ((fft[Filter]) AND (humans[Filter]) AND (english[Filter]))

\section{Mobile Application Dentistry Drug Information Filters: Full text, Humans, English}

(("mobile applications"[MeSH Terms] OR ("mobile"[All Fields] AND "applications"[All Fields]) OR "mobile applications"[All Fields] OR ("mobile”[All Fields] AND “apps"[All Fields]) OR “mobile apps”[All Fields]) AND (“dentistry”[MeSH Terms] OR “dentistry”[All Fields] OR "dentistry s"[All Fields]) AND "drug"[All Fields] AND ("inform"[All Fields] OR "informal”[All Fields] OR "informality"[All Fields] OR “informally"[All Fields] OR "informant"[All Fields] OR “informant”[All Fields] OR “informants"[All Fields] OR “information”[All Fields] OR “information"[All Fields] OR "informational"[All Fields] OR “information”[All Fields] OR “informative"[All Fields] OR "informatively"[All Fields] OR "informativeness"[All Fields] OR “informativity"[All Fields] OR "informed”[All Fields] OR “informer"[All Fields] OR “informers"[All Fields] OR “informing”[All Fields] OR “informs"[All Fields])) AND ((fft[Filter]) AND (humans[Filter]) AND (english[Filter]))

Mobile Application Dentist Drug Information Filters: Full text, Humans, English

(“"mobile applications"[MeSH Terms] OR ("mobile"[All Fields] AND "applications"[All Fields]) OR "mobile applications"[All Fields] OR ("mobile"[All Fields] AND "apps"[All Fields]) OR "mobile apps"[All Fields]) AND ("dentist s"[All Fields] OR "dentists" [MeSH Terms] OR "dentists"[All Fields] OR "dentist"[All Fields]) AND "drug"[All Fields] AND ("inform"[All Fields] OR "informal"[All Fields] OR "informality"[All Fields] OR "informally"[All Fields] OR "informant"[All Fields] OR "informant"[All Fields] OR "informants"[All Fields] OR "information"[All Fields] OR "information"[All Fields] OR “informational”[All Fields] OR "information"[All Fields] OR "informative"[All Fields] OR "informatively"[All Fields] OR "informativeness" [All Fields] OR "informativity"[All Fields] OR "informed"[All Fields] OR "informer" [All Fields] OR "informers"[All Fields] OR "informing"[All Fields] OR "informs"[All Fields])) AND ((fft[Filter]) AND (humans[Filter]) AND (english[Filter]))

As a result, no studies came up with it. Another search had been done if pharmacy textbooks of the drug information and some google searching engine, and Apple stores. The authors employed drug information resources as websites or drug information resources websites for dental medication inquiries and secondary or tertiary drug information resources. The author intended some parameters to recapitulate the drug information mobile applications appropriate for the dental care. The inclusion criteria of mobile applications were all applications available in Saudi Arabia iTunes Store or Google play store, evidence-based support by preceding literature or textbook publications, and positive reviews by the authors.

In comparison, omitted criteria were written in non-language, pharmacy, or medical applications negative reviews. Each resource summary entailed of name of resource, content, inquiries answered, type of resources, number of medications or journal covered, frequently update, last edition, price and subscription. It also includes publisher, manual book, online version, website address, application type, usage of dental student recommendations, usage of the general dental practitioner, usage of specialized or consultant dentist, dentistry specialties.

\section{RESULTS}

\section{Assessment of Needs}

E-Health refers to using the literature information and communication technologies (ICT's) in the health sphere to administer treatment of patients, research, health education, and public health monitoring. ${ }^{5}$ The World Health Organization outlines e-health as the usage of information and communication technologies (ICT's) in the health domain to treat patients, research, health education, and public health monitoring. ${ }^{5}$ The need to employ drug information applications has a positive influence on improving the outcomes of drug therapy. The provision of non-biased and authentic information can help reduce drug-related complications and promise drug safety to an extent in all dentist settings. The dentist must know how to deliver accurate and complete responses following their case through efficient use of drug information applications that is an essential skill for all healthcare providers to have regardless of their practice site. One of the conventional methods of new project assessment is the SWOT analysis. It defines strengths, weaknesses, opportunities, and threats of the project. ${ }^{6}$ This project's strengths are introducing drug information application or even list for most vital dentist drug application, which complicated in actual and appropriate activities, preventing drugrelated mistakes, and an additional unnecessary. The weaknesses of this project are disregarding the service.

Moreover, there is no education or guidance in the usage of drug information applications, Difficulties in supporting and funding for these services. The opportunities in this project are the implementation of accreditation standards and the availability of dentists aware of drug information applications. The threats to this project are there is no dentist interested in this field and the planning of dentist drug information applications.

\section{Project Description}

The scope of the current project is to assert the dental drug information mobile applications. The vision of the current topic is to influence the best with high-quality dental drug information applications, while the mission to deliver cost-effective dental drug information applications. The project's goals are to select the best and apprise dental drug information applications, to offer education and training for dental staff, and document the echo of dental drug information applications on the dental care. During the project implementation actions, the management team contained of the team's experts organizing the dentist drug information application: the team involves of clinical pharmacists, expert pharmacists and pharmacy technicians expert in drug information, dentists, dentists assistant, nursing and information technology member. The team should instruct and train the dentist and dentist's assistant to apply drug information-related issues. The team should set-up new policies and procedures linked to the drug information services, monitor the implementation of the software, and evaluate the outcome with the economic impact of the new services. One of the essential things are to implement a drug information application (the financial budget). The budget should reflect cost-related issues, counting education and training. Besides, the cost of equipment is needed for the preparation and the management team meetings. The defined budget should be scrutinized throughout the project period implementation. The dentist staff needs to appear numerous courses of drug information searching skills. Besides, the best application 
resources of updated information of drug therapy for some diseases and basic pharmacology. Also, the education on drug information centers is stability research. The project wants to highlight total quality management keys called Balance Scored Card as key performance indicators of dental applications of drug information resources with different types, counting the customer, finance, internal process, education, and innovation. ${ }^{7}$ There are risks in the current project: budget, scope, personnel, scheduled, technical, and quality risks. This project might be unprotected to the personnel risk due to the shortage of expert dentists. It might also be exposed to budget risk. It strains a budget to cover the education and training of dentist staff.

Moreover, the project might also be bare to technical risks such as material was not being available. Quality risks are met due to the untrained dentist being available. ${ }^{8,9}$ There is nine mobile software suitable for the dental providers elucidated in the current topic, while twenty-three mobile applications are correctly deliberated, as explored in Table 1-3.

\section{DISCUSSION}

The dental drug information resources journey underway from the regular textbook, then converted to pdf at CD. By the time, sometimes the textbook came as a text page at the website, it commenced converting to the old mobile model of blackberry, their final stage of windows operating system or android or recently Hawaii. ${ }^{1}$ So, there are still coming as a textbook and mobile applications at the same time. For example, some of the applications came from the textbook, such as Lexi-drug comp, statref, and related books about dental drug information resources. Some governmental websites had distinct applications like FDA, CDC, and $\mathrm{MOH}$, as declared in Table 2. In addition, they conversed general healthcare, counting dental medications.

Some organizations enatils free websites with either pure website of drug information like drug.com or treatment of dental medications management. Other applications depends as part of evidence-based dentistry. They had unusual applications for these websites like clinical key or Cochrane library, as list explored in Table 2. However, there are some pure applications not associated to any type above. For occurrence, skyscape applications. Its collection of mobile applications, and intended for many specialties, counting dental drug information resources. Few were free software and some by subscription. The skyscape and Medhand library applications look like the StatRef applications list (which is less often used by dentists). ${ }^{10}$ Two applications dedicated in dental drug information resources called clinical advisor, dental drugs, and dental clinical mastery (which are less frequently used by the dentist. ${ }^{10}$ They conferred the dental medications in summary with pharmacological classification. Additional mobile applications like Epocrates discussed in-depth detail dental and non-dental medications. ${ }^{4}$ Some of them came as a website and applications. It look like the Lexi-drug comp application. There is one software that discoursed dental terms and definitions. In addition, there is another software support for dental specialties with dental nurses called IV Medications Handbook Gahart. Some software came as free with website subscription-like EBSCO mobile, Clinicalkey, or Cochrane library. Other software came free of charge with their website with abridged information like FDA, SFDA, and $\mathrm{MOH}$.

The choice of mobile applications is reliant on various factors. According to earlier literature, there are multiple methods to select any mobile application. ${ }^{11-13}$ First, it depends on the benefits and quality of mobile software imitated in practice like skyscape group or Lexi-comp group or statref group or Epocrates. ${ }^{2-4}$ The second factor that might impact the choice of applications is the cost. Many software applications came free of charge and might be very appropriate for dental students or new dental practitioners. Additional factors that might move the usage of mobile applications related to dental drug resources are the types of

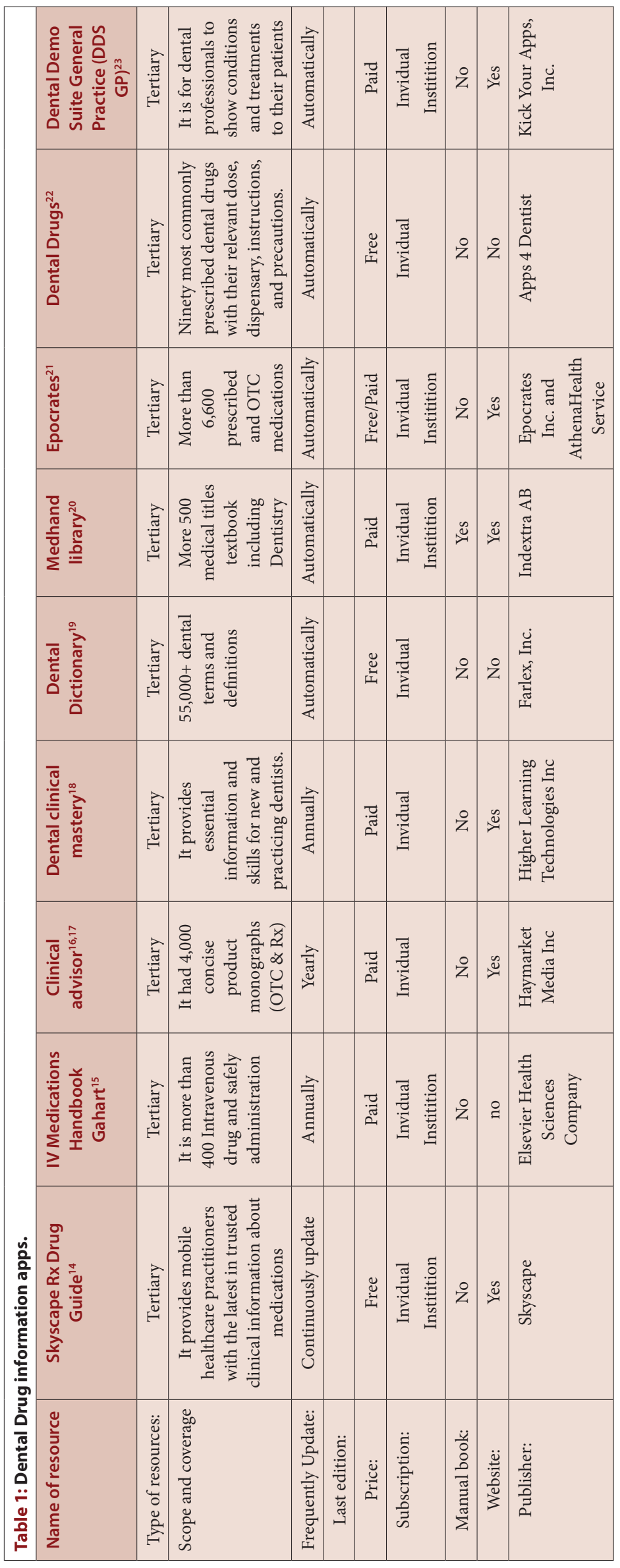




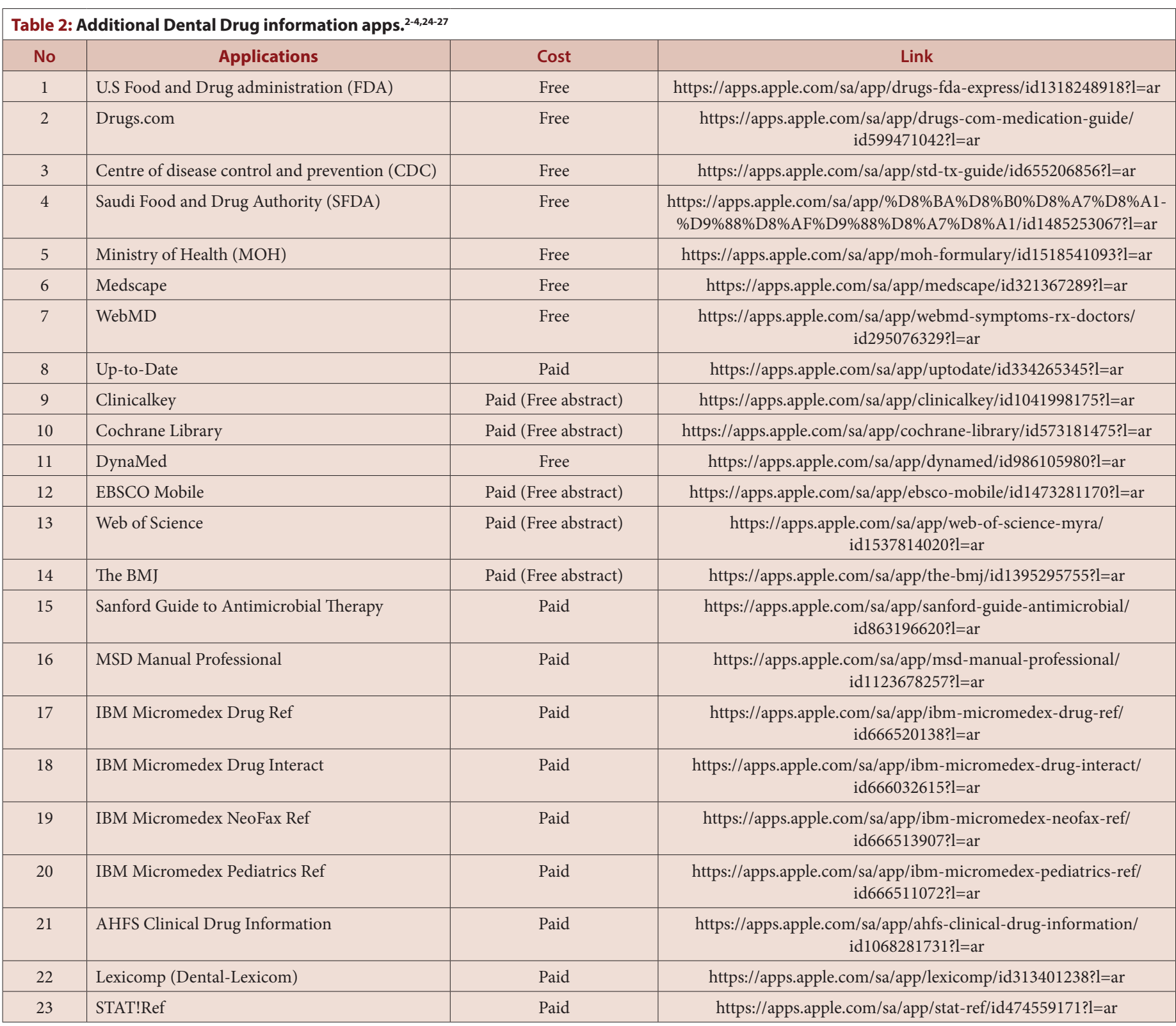

formats. For instance, some software came as a website, applications, and regular textbook-like group of Lexi-comp. Lead to many users exploited based on practitioner preference. Healthcare organizations, including dental colleges, should review all mobile applications, choose appropriate, and make their staff and student mandate.

\section{CONCLUSION}

Most drug information dental textbooks or dental websites and evidencebased dentistry desired mobile applications in the current century. There is an underutilization of drug information dental applications by professional dentists. Moreover, few or nil studies review the usages of the dental application. The new initiative project with allocated team and support of logistic and financial budget at the dental healthcare organizations will recover the use of new technologies in dental practice. Implementing dental medication applications in the undergraduate dental college will rally dental services and reflect on dental drug medication safety during dental care in Saudi Arabia.

\section{ACKNOWLEDGEMENT}

None.

\section{CONFLICT OF INTEREST}

The authors declare that there is no conflict of interest.

\section{ABBREVIATIONS}

MOH: Ministry of Health; KSA: Kingdom of Saudi Arabia; SWOT: Strengths, Weaknesses, Opportunities, and Threats; FDA: Food and Drug Administration; SFDA: Saudi Food and Drug Authority; BSC: Balanced Scored Card; ICT's: information and Communication Technologies); DDS GP: Dental Demo Suite General Practice; FDA: U.S Food and Drug administration; CDC: Centre of disease control and prevention.

\section{Funding}

None

\section{Consent for Publications}

Informed consent was obtained from all the participants 


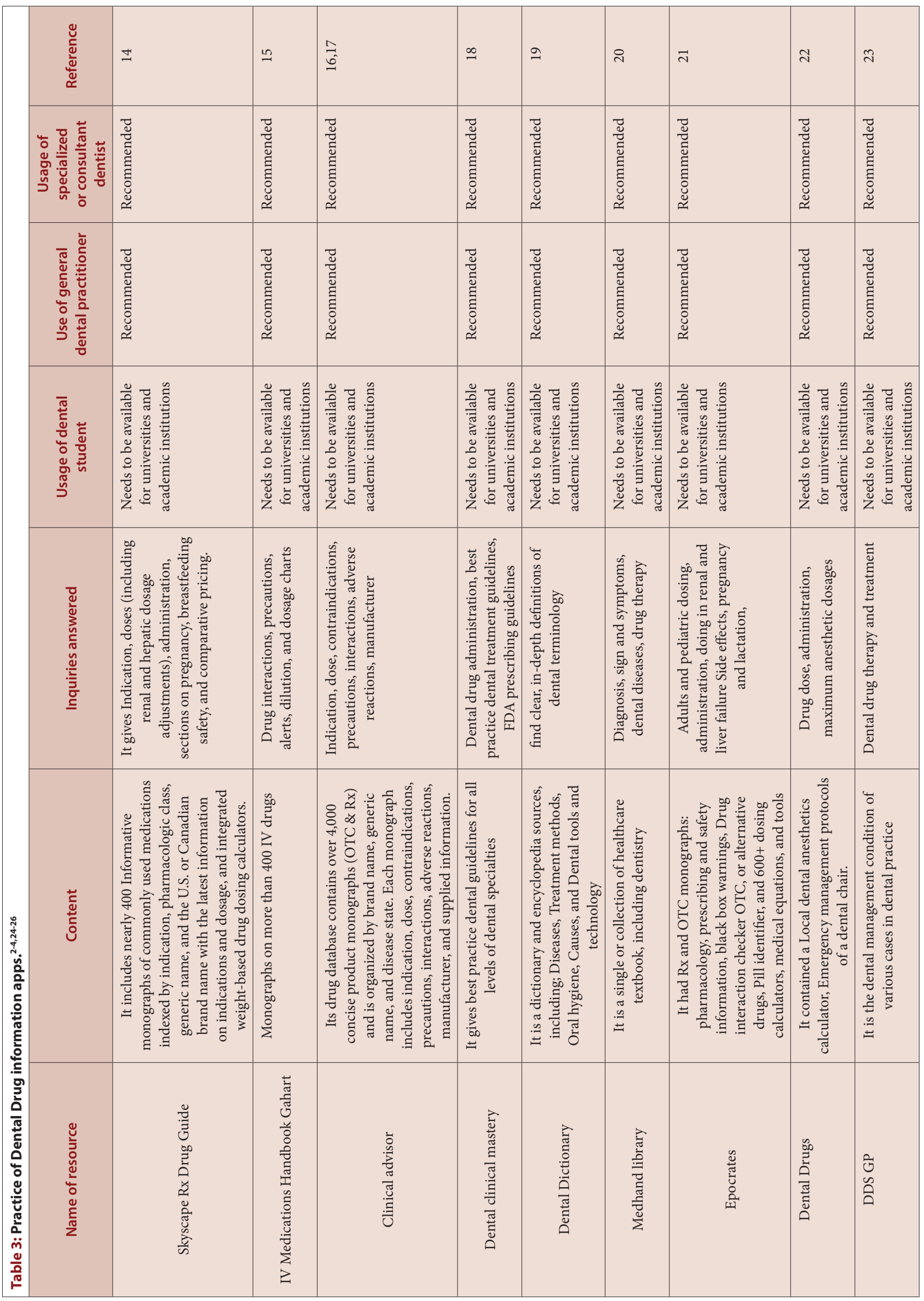




\section{Ethical Approval}

This research was exempted from research and ethical committee or an institutional review board (IRB) approval.

https:/www.hhs.gov/ohrp/regulations-and-policy/decision-charts-2018/ index.html

\section{ORCID ID}

Yousef Ahmed Alomi iD https://orcid.org/0000-0003-1381-628X

\section{REFERENCES}

1. Elnaem M, Jamshed S. Mobile applications in clinical practice: what is needed in the pharmacy scenario? Arch Pharma Pract. 2017;8(1):3. doi: 10.4103/2045080X.199619.

2. Alomi YA, Alshammari AM, Saleam Aljohani HS. Dentist's knowledge of evidence-based dentistry and digital applications resources in Saudi Arabia. PTB Reports. 2021;7(1):23-7. doi: 10.5530/PTB.2021.7.5

3. Aungst TD. Medical applications for pharmacists using mobile devices. Ann Pharmacother. 2013:47(7-8):1088-95. doi: 10.1345/aph.1S035, PMID 23821609.

4. Rebedew D. Six mobile apps to make prescribing easier. Fam Pract Manag. 2018;25(6):11-6. PMID 30422612.

5. e-Health-an overview. ScienceDirect Topics [Internet]. [cited 2021 Jun 24]. Available from: https://www.sciencedirect.com/topics/medicine-and-dentistry/ehealth

6. Helms MM, Nixon J. Exploring SWOT analysis - where are we now?: a review of academic research from the last decade. Journal of Strategy and Mgt. 2010;3(3):215-51. doi: 10.1108/17554251011064837.

7. Enwere EN, Keating EA, Weber RJ. Balanced scorecards as a tool for developing patient-centered pharmacy services. Hosp Pharm. 2014;49(6):579-84. doi: 10.1310/hpj4906-579, PMID 24958976.

8. Ray S. The risk management process in project management - ProjectManager.com [internet]; 2017. Project Manager [cited Mar 15 2020]. Available from: https://www.projectmanager.com/blog/risk-management-process-steps.

9. Kaplan RS, Mikes A. Managing risks: A new framework [internet]; 2012. Harvard Business Review [cited Mar 15 2020]. Available from: https://hbr.org/2012/06/ managing-risks-a-new-framework.

10. Alomi YA, Alshammari AM, Aljohani HSS. Dentist's knowledge of essential drug information resources in Saudi Arabia. PTB Reports. 2021;7(1):17-22. doi:
10.5530/PTB.2021.7.4

11. Barrons R. Evaluation of personal digital assistant software for drug interaction. Am J Heal Syst Pharm. 2004;61:380-5.

12. Hanrahan C, Aungst TD, Cole S. Evaluating Mobile Medical Apps. ASHP eReport. 2014.

13. Stoyanov SR, Hides L, Kavanagh DJ, Zelenko O, Tjondronegoro D, Mani M. Mobile app rating scale: a new tool for assessing the quality of health mobile apps. JMIR mHealth uHealth. 2015;3(1):e27. doi: 10.2196/mhealth.3422, PMID 25760773.

14. Skyscape RxTM - drug guide | skyscape mobile app and web [internet] [cited Apr 11 2021]. Available from: https://www.skyscape.com/product/Skyscape-RxDrug-Guide.

15. Intravenous medications. Vol. IV. Drug guide GAHART - apps on google play [internet] [cited Apr 11 2021]. Available from: https://play.google.com/store/ apps/details?id=com. medpresso.Lonestar.ivmed\&hl=en.

16. Clinical advisor app download [internet] [cited Apr 11 2021]. Available from: https://www.clinicaladvisor.com/home/clinical-advisor-app-download/.

17. Clinical advisor - apps on google play [internet] [cited Apr 11 2021]. Available from: https://play.google.com/store/apps/details?id=com.usbmis.troposphere. clinad\&hl=en_US.

18. Dental clinical mastery on the app store [internet] [cited Apr 11 2021]. Available from: https://apps.apple.com/us/app/dental-clinical-mastery/id1183950374.

19. Dental dictionary [internet] [cited Jun 19 2021]. Available from: https://apps. apple.com/sa/app/dental-dictionary-by-farlex/id1021593596?|=ar.

20. MedHand mobile libraries app store [internet] [cited Jun 192021]. Available from: https://apps.apple.com/sa/app/medhand-mobile-libraries/id557073873?l=ar.

21. Epocrates on the app store [internet] [cited Jun 19 2021]. Available from: https:// apps.apple.com/us/app/epocrates/id281935788.

22. Dental drugs [internet] [cited Jun 19 2021]. Available from: https://apps.apple. com/sa/app/dental-drugs/id1010795610?|=ar.

23. Patten C. Hello Bracket Table, Meet iPad. Dent Mag [Internet]. 2011 [cited 2021 Aug 24];244. Available from: https://www.dentaltown.com/dentaltown/article. aspx?aid $=3206$

24. Malone PM, Kier KL, Stanovich JE. Drug information: A Guide for pharmacists. 3rd ed; 2006.1-877.

25. Gabay M. The clinical practice of drug. Information. 2016.1-539.

26. Kier KL, Goldwire M. Drug information resources and literature retrieval. 2018. 619-45.

27. Lin M, Rezaie S, Husain I. Top 10 mobile apps in Emergency Medicine. Emerg Med J. 2014;31(5):432-3. doi: 10.1136/emermed-2014-203607, PMID 24567149. 